\title{
Exploration and Practice of Cooperative Education Mode of "Production, Learning, Research and Innovation" in Higher Vocational Colleges
}

\author{
Haiyu $\mathrm{Li}^{1}{ }^{1,}$, Lei Wang ${ }^{1}$,Wenhuan $\mathrm{Niu}^{1}$, Xiaoyan Yang ${ }^{1}$ and Guangzhen $\mathrm{Xu}^{1}$ \\ ${ }^{1}$ School of Mechanical and Electrical Engineering, Weifang Vocational College, No. 06588 hai 'an Road, Science and \\ Education Innovation Park, Binhai Economic and Technological Development Zone, Weifang City, Shandong \\ Province
}

*Email: 710859920@qq.com

\begin{abstract}
Deepening the integration of Industry and education is an urgent requirement to push forward the supply-side structural reform of human resources. In this paper, the production training base, Vocational Education Group and other integration platform as the main research object, explore higher vocational colleges "production, learning, research and innovation" collaborative education model and path, service regional economic development.
\end{abstract}

Keywords: Integration of production and education; production, learning, Research and Innovation; Collaborative Education

\section{BACKGROUND}

In the report of the 19th National Congress of the Communist Party of China, it is proposed to "strengthen the construction of the national innovation system, and establish a technology innovation system with enterprises as the main body, the market as the guide, and the indepth integration of the industry, universities and research institutes", so as to form an industry-UniversityResearch cooperation system with complementary resource advantages and coordinated development of main bodies [1]. In 2019, China's Government Work Report proposed to "improve the enterprise-universityresearch integration innovation mechanism with enterprises as the main body". With the in-depth cooperation between the industry, the university and the research institute, the state has put forward higher requirements and standards for the collaborative innovation mode and innovation ability of the industry, the university and the research institute, and raised the cooperation to a national strategic height. In the face of promising development opportunities and unprecedented challenges in Higher vocational education in China, it is the top priority of current vocational education as well as the core competitiveness of sustainable development of schools to construct a new mode of "industry-universityresearch-Innovation" collaborative education, build a new plateau of high-quality technical and technical personnel training, and serve regional economic and social development.

The foreign cooperative innovation model of production, learning and research is comprehensive and integrates schools, research institutions and enterprises seamlessly. Its mode construction is worth learning and using for reference. In the United States, the government plays a leading role in the collaborative innovation of Industry, university and Research, and the typical models include the Business incubator model, the university science park model and the Engineering Research Center model. Korea focuses on the Joint R \& D model with the needs of enterprises as the core, while Japan focuses on joint research and commissioned research. Compared with foreign countries, our country put forward the development idea of the cooperation of industry, university and research relatively late. The research in the field of industry, university and research has the characteristics of multi-form, multi-level and multioptimization. The researchers can grasp the mainstream research focus, this paper makes theoretical and practical research on the cooperation innovation of Industry, university and Research Institute from different breadth and depth [2]. However, in the new era, the research of Industry, university, Research, Innovation and 
collaborative education needs further practice and exploration.

In the new era, relying on the platform of integration of industry and education, such as productive training bases and key vocational education groups, we will carry out the practice and research of "industry, education, research and innovation" to promote the development of "dual" education mechanism in Shandong Province, it is of great significance to promote the reform of "three religions" . In the new era, we should actively explore a new mode of deep cooperation between schools and enterprises under the background of integration of industry and education, establish a good cooperation mechanism between schools and enterprises and a mode of cooperative education of production, teaching, research and innovation, and carry out the practice and research of cooperative education of "production, learning, research and innovation", it is of great theoretical significance to provide decision-making reference for promoting the construction of the mechanism of integration of industry and education in Shandong Province, and to provide a new direction for the reform of "three religions" in higher vocational colleges. Deepening the integration of production and teaching is the key way to realize the effective link between school training and enterprise employment, it is of great significance to improve the quality of education, expand employment and entrepreneurship, promote economic transformation and upgrade, and foster new driving forces of economic development. Industryuniversity-research cooperation in pursuit of social and economic benefits under the background of "double-high plan". In this paper, the SMT national production training base, Shandong Province backbone vocational education group and other production and education integration platform as the main research object, explore higher vocational colleges "production, learning, research and innovation" collaborative education model and path, service regional economic development, at the same time for the integration of Industry and education, schoolenterprise cooperation to explore the practice. As a national production training base, SMT production training base is also typical, which has certain practical value for the popularization and application of this model.

\section{OPERATION}

\subsection{Exploring the long-term mechanism of school-enterprise cooperation}

Under the premise of the active function of the local government, the Cooperation Council of "administrative school-enterprise research" has been established, so as to realize the sharing of resources, complementary advantages, mutual benefit and common development, and promote the rapid and high-quality development of vocational education [3]. Further cooperation between schools and enterprises, the establishment of a "doubleagent" education mechanism, to enhance the enthusiasm of enterprises in vocational education. To strengthen communication between higher vocational colleges and cooperative enterprises so that enterprises can have a better understanding of the school-running mode of "double-main-body" education, the cooperative enterprise contributes to the professional setting, curriculum reform, the construction of teachers and the formulation of talent training plan, and participates in the whole process of talent training in higher vocational colleges. In the process of "production, study, research and Innovation", school and enterprise cooperate closely, the two sides break the situation of each other, improve service consciousness, improve talent training mode, and highlight the status of "double main body" of enterprise and Higher Vocational College. The form of close cooperation between school and Enterprise is determined according to the actual situation, such as modern apprenticeship training, "order form" training mode and so on.

\subsection{Constructing cooperative education mode of "production, learning, research and innovation"}

This project is supported by the surface-mount technology key laboratory of Weifang, taking platforms such as SMT national production training base, national skill master workshop, Shandong Backbone Vocational Education Group, Shandong Vocational Education Skill inheritance and innovation platform, Weifang NC Engineering Technology Research Center, Weifang key laboratory for precision manufacturing of key parts of magnetic levitation blower, master workshop, etc. As research objects, set up "production, learning, research and Innovation" collaborative innovation center, divided into the production department, Teaching Department, Research and Development Department and Innovation and Entrepreneurship Department, through "production and training projects, teaching and integration projects, cooperative research projects, collaborative innovation projects, " to coordinate the "production, learning, research and innovation" activities, to explore the cooperative education mode of "production, learning, research and innovation" , and to carry out practical research. "

First, production training projects. The Production Department of the "production, learning, research and innovation" collaborative innovation center is mainly responsible for docking with enterprises, with enterprise engineers acting as department managers to undertake real orders from enterprises, full-time teachers and enterprise engineers jointly organize students to carry out productive practical training in the production training base of the university, and integrate the corporate culture with the campus culture. The students participate in the 
production order production of the enterprise in the production post with actual weapons, we should carry out productive training according to the production flow and operation standard of enterprises, improve the students' professional ability and quality, and export a large number of high-quality laborers and skilled personnel for the service of regional economic development.

Second, the teaching project. The Teaching Department of the Cooperative Innovation Center is mainly responsible for transforming the production tasks of the enterprises' orders into teaching projects. First of all, it breaks the traditional teaching method of logically arranging courses based on the boundary of subject knowledge and knowledge system, reforms the traditional teaching method, and explores the deep integration of production and teaching as well as innovative teaching methods, to form a real case of the enterprise as a project into the teaching process of teaching methods, and production processes to identify jobs and teaching projects. Taking the SMT course of surface mount technology as an example, the seven production processes of SMT (in order of production process: 1 Material Inspection 2 solder paste printing 3 surface Mount Component Patch 4 reflow soldering 5 inspection 6 repair 7 cleaning), we divide the course into seven corresponding projects, that is, seven production posts, undertaking enterprise orders, carrying out projectbased teaching in the form of productive practice training, and taking the products of productive practice training as the final examination papers of students, this not only solves the difficult problem of the disconnection between teaching and production, but also cultivates the students'6s management idea and the spirit of craftsmanship.

Third, cooperative research projects. The R \& D Department of the Collaborative Innovation Center is mainly responsible for $\mathrm{R} \& \mathrm{D}$, Promotion and application of applied technology. The school-enterprise cooperation forms the research and Development Group, carries on the classification research which the enterprise meets in the production process the question and the difficult problem, the school-enterprise cooperation carries on the key technical difficult problem to tackle the key problem and the vertical and horizontal topic research, melts into the profession new technology, the new craft, the new standard, at the same time, technology transformation and popularization and application will be carried out, and scientific research projects will be further transformed into teaching projects, so as to enhance fulltime teachers' engineering practice ability, professional practice ability, teaching and scientific research level and social service ability, train the students to use professional knowledge to solve the actual problems of the enterprise vocational ability.

Fourth, collaborative innovation projects. At present, the integrated platform of group production and education of electrical automation technology in our college mainly includes Weifang Key Laboratory of Surface Mount Technology, school-enterprise co-built SMT national productive training base, teachers' innovation team and professional associations of college students. Relying on the integration platform of production and education of all types and at all levels, university-enterprise cooperation set up a "production" collaborative innovation center business department, mainly responsible for the problems in enterprise production into innovative start-ups, organization research and analyze the teachers and students to select the appropriate project, "Internet + " competition at various levels and innovation business class competition, such as project, and the innovative start-ups into teaching explore double gen ability between teachers and students, the cultivation of comprehensive practice ability.

\subsection{Building "production, learning, research and innovation" talents training highland}

Aiming at the field of regional intelligent manufacturing equipment, we will deepen the integration of school-enterprise production with teaching, carry out production, study, research and creation in coordination with educating people, and take the training of students'post professional ability and internalization of craftsman spirit as the main line, "administrative schools, enterprises and research institutes" shall coordinate production, teaching, technological research and development, product upgrading, and incubate innovative and entrepreneurial projects, while transforming incubation projects and production tasks into teaching projects, cooperate with all parties to participate in professional construction, curriculum construction and personnel training, enterprise culture introduction, real-time linkage, "production, learning, research and innovation" into the whole process of personnel training, truly realize the integration of production and teaching, creating a high ground for the cultivation of "production, learning, research and innovation" talents, in order to serve the local economy in the region, we need to train a large number of highquality workers and technical talents who are strong in ideology, politics, morality and technology, meet the needs of the first line in the field of intelligent manufacturing, have good professional ethics and dedication spirit, and have all-round development of morality, intelligence, Physique, art and labor.

\section{RESULTS}

The construction of National SMT Production Training Base and production-education Integration Platform, such as Weifang Mechanical and Electrical Equipment Vocational Education Group, is the key task of the school's double-high construction, based on the National Strategy and industrial development, we should 
seize the favorable opportunity to build a high ground for innovative development of National Vocational Education jointly by the ministry and the province, and strive to be the forerunner and the front-runner of "leading reform and supporting development" . Sticking to the integration of industry and education as the main line, focusing on regional high-end industries and highend industries, implementing the "school-enterprise dual" cooperation mechanism of "co-construction, comanagement and sharing", and deepening the reform of the school-running system and the education mechanism, we will build a new plateau for talents and a new platform for the integration of industry and education.

In recent years, teachers and students actively participate in school-enterprise cooperation, in-depth integration of production and education projects, to participate in enterprise order production. Taking our national SMT production training base as an example, the base is used by students majoring in applied electronic technology for more than 1,000 hours of production training each year, and is responsible for over 5 million production orders, schools and enterprises cooperate to carry out vertical and horizontal research projects, relying on productive training bases, set up 5 nationallevel research projects, 8 provincial-level research projects, 15 municipal-level research projects, and more than 20 horizontal projects, vertical and Horizontal Science and technology to the amount of more than 1 million yuan, for enterprises to improve economic efficiency of more than 40 million yuan, at the same time in personnel training, professional construction, curriculum construction, loose-leaf type and work manual type of new teaching materials, etc. , teachers' ability of engineering practice, professional practice, education and teaching, scientific research and social service have been greatly improved, and students' technical skills have also been greatly improved, it provides a strong support for the improvement of the talent training level of the school.

Since the establishment of the Weifang Machinery and Electrical Equipment Vocational Education Group, it has continuously deepened the integration of production, education and the collectivized running of schools, the member schools were shortlisted in four national highquality schools, four high-level vocational schools with Chinese characteristics and four units of the specialty construction plan, and 38 national backbone specialties, it has 11 provincial level vocational education and 12 high level professional groups with Chinese characteristics, 12 national production training bases and 3 national skill master studios, cooperation between schools and enterprises 2 modern apprenticeship pilot projects of the Ministry of Education and 16 modern apprenticeship pilot projects at the provincial level. The total value of equipment donated by the member units of the vocational education group is nearly 10 million yuan, which has improved the hardware level and running strength of our school. In 2019, Weifang electrical and Mechanical Equipment Vocational Education Group was selected as the first vocational education group.

\section{CONCLUSION}

On the one hand, the Cooperative Innovation Center of "production, learning, research and innovation" has been set up, and the four-in-one cooperative education mechanism of "production, learning, research and innovation" has been set up, it enriches the form and connotation of cooperation [4]. On the other hand, we should integrate superior resources, jointly establish the goal and standard of talent cultivation, jointly construct the curriculum system, jointly allocate teaching resources, jointly participate in the whole process of student cultivation, introduce corporate culture in the whole process, and interact with each other in real time, to realize the integration of production and education, and to build the highland of "production, learning, research and innovation" talents cultivation.

\section{REFERENCES}

[1] Xiaoya Chen. Pool Wisdom and strength to promote the deep integration of production, learning and research $[\mathrm{J}]$. China's science and Technology Industry, 2018(1): 20-21.

[2] Tianqi Yu. Research on collaborative innovation model of Industry, University and Research: A Literature Review [J]. Industrial Technology Economy, 2019(7): 88 -- 92.

[3] Wenlong Gui, Qizhi Zhu, Huagen Yuan. Innovation and practice of "government-execution schoolenterprise" cooperative school-running system and mechanism in higher vocational colleges [J]. Vocational Education Research,2014(2):5-8.

[4] Zhenzhen Jiang, Junren Zhu. Research on the mode of "four-in-one" cooperative education of industry, university, research and application under the background of double creation [J]. Youth, 2019(16): 183 -- 184. 